\title{
When Was Westerhus Churchyard in Use?
}

\author{
Claes-Henric Siven
}

\begin{abstract}
The period of use for the Swedish medieval churchyard of Westerhus has been estimated by the maximum likelihood method. Raw data consist of 30 calibrated ${ }^{14} \mathrm{C}$-dates of some of the skeletons from the site. Bias and other properties of the maximum likelihood estimator are analyzed via a number of Monte Carlo simulations. The point estimates imply that the site was used in the period 1073-1356, that is, a somewhat longer period than previously assumed. The estimated length of the period of use affects the interpretation of the great number of buried children. Population calculations lead to the conclusion that the six agglomerations of children's graves cannot be interpreted as mass graves.
\end{abstract}

Claes-Henric Siven, Department of Economics, Stockholm University, SE-106 91 Stockholm, Sweden.

Key words: Maximum likelihood method, Monte Carlo simulations, ${ }^{14} \mathrm{C}$ dates, medieval churchyard, infant burials, Sweden.

The medieval churchyard of Westerhus at Frösön in the province of Jämtland in Sweden is often used as an object of reference when studying populations from the Middle Ages. ${ }^{1}$ One reason for this is Nils-Gustaf Gejvall's path-breaking osteoarchaeological analysis of the site, published in his doctoral dissertation in 1960.

The recent project "People of the medieval period" has used Westerhus as one of its starting points. Redin (2000) focuses his analysis on social history and the method of archaeological excavation. He discusses the time period during which the churchyard was used, whether a wooden church preceded the stone chapel and, finally, the relationship between Westerhus and the nearby Frösö Church. To date Westerhus, Redin has used conventional archaeological methods (the shape of the chapel and the positioning of the upper extremities of the dead) as well as results from ${ }^{14} \mathrm{C}$-dating. The latter information can be found in Kylberg \& Strucke (2000).

The well-preserved skeletal material from Westerhus has made possible, among other things, investigations of the diet of children and grown-ups, using the analysis of trace elements (see Iregren, Jungner, Räisänen \& Alexandersen 2000). Another example is the analysis of the health of children as reflected by the condition of their teeth, see Alexandersen \& Iregren (2000). Closely connected to the health

\footnotetext{
' Tirup in Denmark is another frequently used Scandinavian object of reference, see Boldsen (2000).
} 


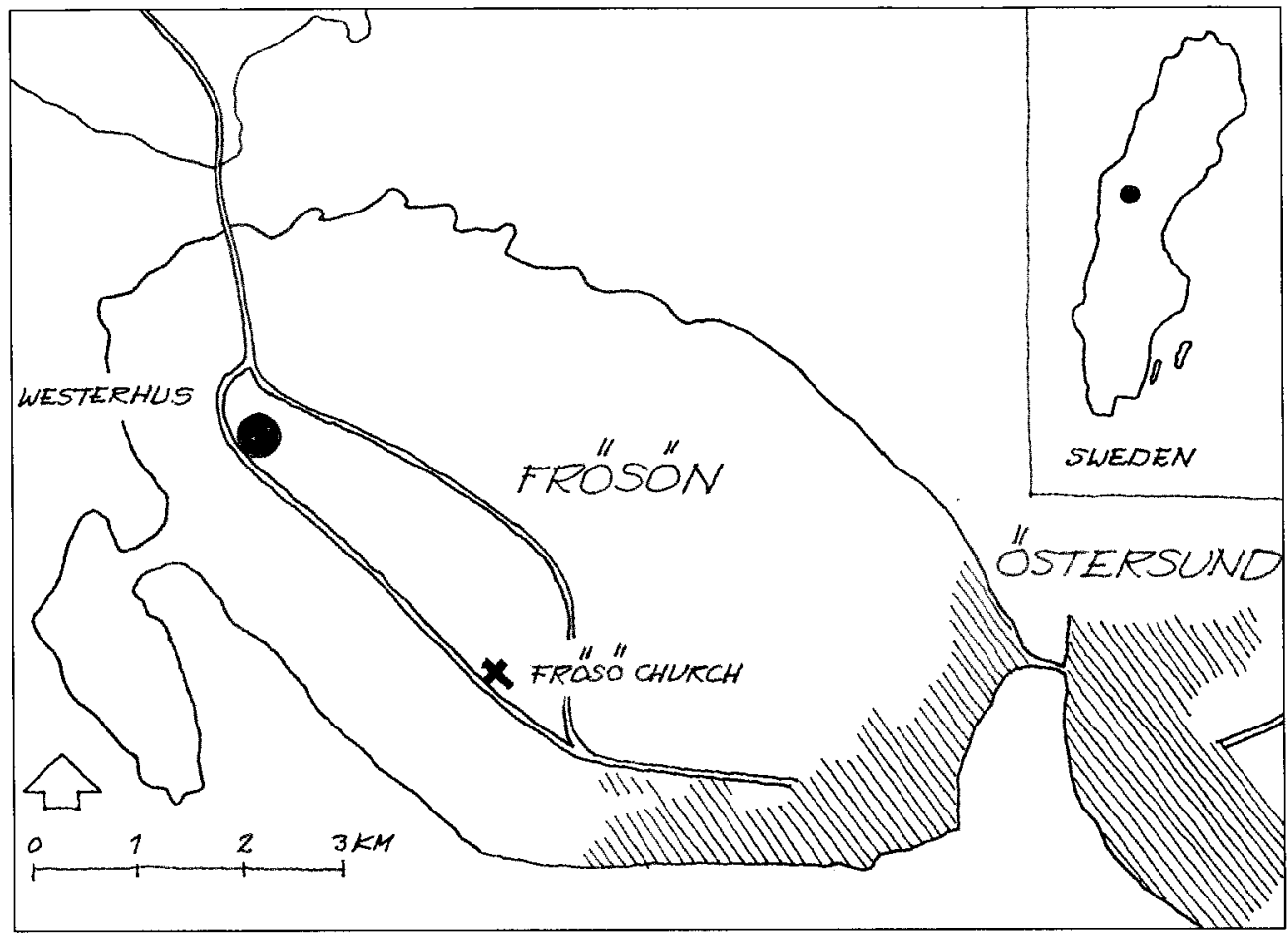

Fig. 1. Map of Frösön.

of the medieval population of Westerhus is the question of how to interpret the six grave agglomerations with children, see Iregren \& Redin (1999). Can the collective graves be interpreted as results of epidemics that mainly affected children? The excavation was not properly documented ${ }^{2}$, and thus we must use indirect methods to answer the question whether the grave agglomerations are really mass burials. For example, was the number of simultaneously living children large enough to explain that up to 22 or 23 children under the age of 15 died in the same season and were buried close to each other?

The dating of Westerhus is not only important for placing the churchyard in a historical context. The length of the period of use for the churchyard also affects inferences concerning the number of people living in Westerhus. Given the number of graves, a shorter period of use implies a larger living population and a greater likelihood of finding many children buried during the same season. The duration of use of the churchyard consequently influences our interpretation of the possible mass burials of children.

Gejvall (1960:129) places the starting year of the churchyard around 1100 and the terminal year around 1350 . The terminal year is connected to the Black Death in $1349-50 .^{3}$ After that, the population was too small to support Westerhus

\footnotetext{
${ }^{2}$ For a discussion of this, see Redin (2000:156).
} 
and it began to use Frösö Church, built around 1200. The start of use can hypothetically be seen as the year when the people ceased using the burial-ground and instead began using the churchyard.

After the publication of Gejvall's dissertation, a number of ${ }^{14} \mathrm{C}$-analyses have been performed. Gejvall (1968) published the results of $12{ }^{14} \mathrm{C}$-analyses. Kyhlberg \& Strucke (2000) present calibrated values of these and eight additional values obtained on the initiative of Iregren and Redin. Based on the series of 20 calibrated values, Kyhlberg \& Strucke (2000) draw the conclusion that the burials took place during the period 1098 - 1292. Redin (2000) uses Kyhlberg's \& Strucke's result, but adds information about burial customs (the positions of the upper extremities). He suggests a shorter period (200 years) of use than Gejvall (1960) (250 years), which would imply a larger simultaneously living population. A larger population would more easily accommodate the hypothetical "mass burials" of children discovered at Westerhus.

The present paper presents a maximum likelihood estimate of the period of use for the churchyard of Westerhus. The estimate is based on the $20{ }^{14} \mathrm{C}$-dates used by Kyhlberg \& Strucke $(2000)$ and 10 new ${ }^{14} \mathrm{C}$-dates provided through the initiative of Elisabeth Iregren and Lars Redin, see Possner \& Söderman (2001). The estimate will be used to interpret the agglomerations of children's graves. Except for tables, dates will usually be given with four digits (the year). This procedure is not followed to create a false sense of precision. Rather, I think it is bad practice to indicate uncertainty by rounded figures. The imprecision should instead if possible be indicated by confidence intervals. ${ }^{4}$

The rest of the discussion will proceed in the following way. First, the estimates of the left and right end points of the time interval will be more precisely formulated. Second, the method of Kyhlberg \& Strucke will be discussed. Then, the maximum likelihood calculations will be presented. Further, the relationship between ${ }^{14} \mathrm{C}$-datings and archaeological dating will be discussed. This discussion concerns the implication of the results for population calculations and problems of social history and archaeology. Do the agglomerations of children's graves represent mass burials?

\section{CALCULATION OF THE MEAN OR AVERAGE YEAR OF USE}

Assume that the problem is to determine the mean of the interval instead of assessing the initial and end points of use of the churchyard. We sample individuals and estimate when they were buried. There are two kinds of errors. First, the ${ }^{14} \mathrm{C}$ analysis is subject to a measurement error of which we know the probability

\footnotetext{
${ }^{3}$ This means that the end of use of the Westerhus chapel is connected to the decline in population and economy in Jämtland following the Black Death. For discussion of the effects of the plague(s) in Jämtland, see Myrdal (2003) and Antonsson (2004).

${ }^{4}$ Scientific reports that give rounded figures to stress imprecision introduce a new kind of error when these figures are used by later researchers.
} 
density function. The measurement error is partly related to the problem of obtaining an exact measure of the ${ }^{14} \mathrm{C}$-contents, and partly to how these errors are transformed when we calibrate the translation of the ${ }^{14} \mathrm{C}$-contents into a calendar year.

The second type of error is a sampling error. Random sampling would lead to a sampling error so that the mean year of the sample would differ from that of the whole material of the churchyard.

Therefore, the estimated mean year will be subject to measurement and sampling errors. Starting from these errors, we can calculate a confidence interval for the mean. In Fig. 2, the mean year will therefore be indicated both by a point estimate, $M$, and a confidence interval (not shown in the figure) around the estimated $M$.

The mean value of the 30 calibrated ${ }^{14} \mathrm{C}$-assessments is 1197.5 . Consequently, this is a point estimate of the mean year of the burials. But the ${ }^{14} \mathrm{C}$-dates are subject to both measurement and sampling errors and the true mean year may differ from the point estimate.

\section{CALCULATION OF END POINTS}

However, the task is not to calculate the mean (average year), $M$, of the burials but the estimates of the end points of the interval, $L$ and $U, 5$ where the same principles are involved. There are both measurement and sampling errors. Taking these errors into consideration, we shall make point and interval estimates of the time of start and end of the period, respectively. Referring to Fig. 2, this means a point estimate of the lower limit, $L$, but also that the imprecision of this estimate is marked via a confidence interval around $L$. In the same way, we get a point estimate of $U$ and a confidence interval around this point.

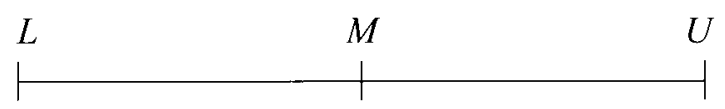

Fig. 2. The period during which the people were buried. $\mathrm{L}$ signifies the estimate of the lower end point, $\mathrm{U}$ of the upper end point, and $\mathrm{M}$ of the mean year of the burials.

However, the confidence intervals for the estimated lower and upper end points ( $L$ and $U$ ) have different properties than that around the mean year $M . M$ is, in principle, affected by all $30{ }^{14} \mathrm{C}$-dates. In contrast, it is in principle only the burial year of the earliest buried individual that affects the placement of the lower end point, while it is only the burial year of the latest buried individual that affects the placement of the upper end point. Consequently, the sampling error has an asymmetric effect. This can also be seen by the fact that, when adding an individual who is assessed as being buried earlier than the individual hitherto thought to be

\footnotetext{
${ }^{5}$ The true value of the mean year of the burials is denoted by $m$ and the true values of the lower and upper end points by $l$ and $u$, respectively. We do not know these values but estimate them with $M, L$ and $U$, respectively.
} 
the earliest, the estimated lower end point of the interval will be moved to the left. In contrast, if the added individual is assessed to have been buried some year in the interior of the interval, the estimated end points will generally not be affected. Abstracting from measurement errors, this means that an added individual can never move the estimated lower end point of the interval, $L$, to the right, but only to the left. In a corresponding way, information from added individuals can never move the estimated upper end of the interval, $U$, to the left but only to the right. New observations can never make the estimated interval shorter, but possibly longer.

The measurement error would not cause any specific problems if we knew the identity of the first and the last individuals buried in the churchyard. We could then use the confidence intervals for the individual who was the first to die for the lower end point, $L$, and the confidence interval for the last to die for the upper end point, $U$. In the absence of this information, we must combine the interval estimates of the year of death of several individuals to obtain the confidence intervals for the lower and upper end points. The maximum likelihood estimator presented below will automatically take into consideration that we do not know for certain who was the earliest or the latest to be buried in the churchyard.

The sampling error is more problematic than the measurement error when constructing interval estimates of $L$ and $U$, because the available ${ }^{14} \mathrm{C}$-dates were not obtained via random sampling of individuals. This means that we cannot say more about the sampling error than that additional ${ }^{14} \mathrm{C}$-dated individuals might lead to a longer estimated period of use of the churchyard, which consequently gives a lower bound. This sounds negative, but a positive aspect should be noted. Observations Ua 15061 - Ua $15068^{6}$ were chosen so as to preferably represent the early part of the period of use, whereas observations Ua-18298 - Ua-18307 should represent the end of the period. This means that stratified sampling was used, which in itself increases the precision of the estimates of the end points.

The problem is now to use the available ${ }^{14} \mathrm{C}$-dates to make point and interval estimates of the starting and terminal years for the period of use of the churchyard.

\section{THE METHOD OF KYHLBERG \& STRUCKE}

Kyhlberg \& Strucke (2000) have calculated point estimates for the upper and lower end points for the period of use of Westerhus. They have started from the interval estimates of the $20{ }^{14} \mathrm{C}$-dates of individual skeletons from Westerhus $(8$ of which are from the Uppsala laboratory and 12 from earlier performed analyses carried out at the Stockholm laboratory). The individual interval estimates are 50-percentage confidence intervals. The choice of confidence level implies that the end points of the confidence interval signify the first and the third quartile, respectively. In the next step, 40 observations are generated out of the 20 individual

\footnotetext{
${ }^{6}$ The $12{ }^{14} \mathrm{C}$-values used by Gejvall were analyzed by the Stockholm laboratory whereas the 8 additional ${ }^{14} \mathrm{C}$-values as well as the last $10{ }^{14} \mathrm{C}$-values were analyzed by the Uppsala laboratory, see Appendix 2.
} 
interval estimates by taking Q1 (the first quartile) for the 20 observations and adding Q3 (the third quartile) for the same 20 observations. With the exception of observation \#19 in the original series of 20 observations, an increasing order was preserved.

In the next step, Kyhlberg \& Strucke calculated the values of the first and the third quartile in the newly constructed series of 40 observations and let both these values represent the point estimates of $L$ and $U$, respectively, for the time period when Westerhus was used.

However, the following step, to rank the Q1- and Q3-values of the individual observations, (on the whole) implies taking the median of the individual Q1values as the initial year of the churchyard, and the median of the individual Q3values as the terminal year of use.

The procedure can be motivated by the fact that the existence of measurement errors may give an upward bias to the estimated length of use of the churchyard. If, as an intellectual experiment, all the dead had been buried at the same point in time, measurement errors would still create dispersion in the measurement values received. It would appear as if the churchyard had been in use during a certain time interval. This is also an argument against presenting the time-span of a settlement with a figure containing the calibrated ${ }^{14} \mathrm{C}$-dates. The eye will namely produce an upward biased estimate of the duration of use of the settlement. Likewise a table containing the calibrated ${ }^{14} \mathrm{C}$-values in increasing order will misrepresent the duration of use of the settlement. ${ }^{7}$ The duration of use should instead be calculated using numerical statistical methods, not "eye-estimation".

The method of Kyhlberg \& Strucke constitutes one possible way of correcting for this positive bias of the length of use. However, a problem with their method is that it is impossible to see whether the method over-compensates for the measurement errors or, alternatively, if it gives insufficient correction of the measurement errors. Using the maximum likelihood method is one way of analyzing this problem.

\section{THE MAXIMUM LIKELIHOOD METHOD}

We shall now estimate the year when people started to use the churchyard and the year when it fell out of use. This can be done by the maximum likelihood method of deriving estimators. ${ }^{8}$ The principle of the maximum likelihood method is simple. The observed data (e. g. the measurement values from Westerhus) are stochastic. In addition to the random element, the measurement values are affected by certain parameters, for example the initial and terminal years of use. The idea is to see which initial and which terminal year of use will maximize the likelihood of receiving the exact measurement values actually obtained. If the 30 dates of

\footnotetext{
${ }^{7}$ In consequence Appendix 2 containing a list of the 30 calibrated ${ }^{14} \mathrm{C}$-values is ordered according to the observation number, not in chronological order.

${ }^{8}$ For a good introduction to the maximum likelihood method, see Cramer (1986) or Severini (2000).
} 
the skeletons from Westerhus are statistically independent, the probability of receiving the obtained measurement values can be written as

$f_{1}\left(x_{1}\right) \cdot f_{2}\left(x_{2}\right) \cdot . . \cdot f_{30}\left(x_{30}\right)$.

However, the received measurement values are influenced by the true dates $y_{1} . . y_{30}$. We do not know their values. Different hypothetically true dates will generate different conditional probabilities of receiving a certain measurement value. Since these hypothetical true dates must lie between the estimated initial year of the churchyard, $L$, and its terminal year, $U$, we can write the probability of receiving measurement value number $i$ as a sum of the conditional probabilities in the following way:

$f_{i}\left(x_{i}\right)=\int_{L}^{U} f_{i}\left(x_{i} \mid y_{i}\right) g\left(y_{i}\right) d y_{i}$

Here, $f_{i}\left(x_{i} \mid y_{i}\right)$ denotes the conditional probability of obtaining a measurement value $x_{i}$ if the true point in time is $y_{i}$. Correspondingly, $g\left(y_{i}\right)$ denotes the probability density function for the true point in time of the burial. Assuming the probabilities to be constant over the period of use of the churchyard, that is, a stationary population ${ }^{9}$, we get

$g\left(y_{i}\right)=\frac{1}{U-L}$.

(3) is then substituted in (2) and thereafter (2) in (1). The problem is then to choose values of $U$ and $L$, thereby maximizing this product of probabilities. In practice, we first take the $\log$ of the function. This does not affect the values of $U$ and $L$ maximizing the (log of the) likelihood function. Consequently, we maximize (4) with respect to $U$ and $L$ :

$-30 \ln (U-L)+\sum_{i=1}^{30} \ln \left(\int_{L}^{U} f_{i}\left(x_{i} \mid y_{i}\right) d y_{i}\right)$

In practice, the maximization will be done numerically using a computer program. ${ }^{10}$

\footnotetext{
${ }^{y}$ For a growing population, the probability density function should not be rectangular. Instead, it should be (exponentially) upward sloping. However, due to non-random sampling errors, there is no simple connection between the development of the population and the probability density function. For example, the $8+10$ latest acquired ${ }^{4} \mathrm{C}$-dates were obtained by stratified sampling. The intention was to obtain observations preferably from the lower and upper end points of the period of use of the churchyard, respectively. To the extent that the intention was realized, the probability of sampling a skeleton buried at a certain date would not be rectangularly distributed. Instead, the distribution would be bi-modal. However, we do not know for certain whether the intention was realized. For simplicity, the assumption of a rectangular function will be maintained throughout.

${ }^{10}$ The calculations have been performed by a series of pascal programs using the Free Pascal compiler. The compiler can be downloaded from http://www.freepascal.org/.
} 


\section{CALCULATION OF THE TIME OF USE OF THE CHURCHYARD}

The calculations will be done using the 20 calibrated ${ }^{14} \mathrm{C}$-dates used by Kyhlberg $\&$ Strucke, and 10 additional calibrated ${ }^{14} \mathrm{C}$-dates produced by the Ångström Laboratory in Uppsala. The measurement values can be found in Appendix 2.

While the measurement errors for the ${ }^{14} \mathrm{C}$ age are approximately normally distributed, the situation is more complex for the calibrated values. Here, the conditional density functions $f_{i}\left(x_{i} \mid y_{i}\right)$ have different functional forms for different observations in the sample. Furthermore, the density functions may be multimodal, asymmetric, et cetera. Preferably, one should start from the actual calculated density functions for the calibrated ${ }^{14} \mathrm{C}$-datings. However, these densities have not been available, and therefore it has been necessary to approximate the functional form with the normal distribution. ${ }^{11}$ Denoting the calibrated year min of an individial observation according to Appendix 1 with $c_{-}$min and the calibrated year max with $c_{-} \max$, the mean value of the individual error function is estimated by $\left(c \_\right.$min $+c_{-}$max $) / 2$ and its standard deviation by $\left(c \_\right.$max $\left.-c_{-} \min \right) / 4$.

Estimated value of the initial year of the churchyard

Estimated value of the terminal year of the churchyard
1085.1

1351.6

Table 1. The estimated initial and terminal years of use. The results are not corrected for the bias of the maximum likelihood method.

The maximum likelihood estimators will generally have good large sample properties. In the present case, the sample consists of only 30 observations. The estimator may therefore be biased and its variance large.

A Monte Carlo experiment was performed to investigate the possible biasedness of the estimator. The 30 calibrated density functions are assumed to be the true ones. Consequently, the assumed starting year will be 1030 and the assumed terminal year of the use of the churchyard $1365 .{ }^{12}$ Assuming normal distributions, the distributions of the measurement errors of the 30 observations have been used to obtain 30 random observations, one from each distribution. The initial and terminal years of use have then been estimated from these 30 experimental observations using the maximum likelihood method. This experiment has been replicated 60,000 times. The resulting distributions of the estimated initial and terminal years of the use of the churchyard are summarized in Table $2 .{ }^{13}$

\footnotetext{
${ }^{11}$ In addition to the graphs, only five measurement points of the cumulate conditional probability density function have generally been available. In order to directly use the calibrated conditional probability density functions, it would be necessary to evaluate these at a great number of measurement points. As a comparison, 100,000 measurement points of the normal distribution have been used. It should also be noted that the published figures have been rounded to the closest multiple of 10 , presumably to indicate the imprecision of the data. However, this introduces another source of error.

${ }^{12}$ See Appendix 1. According to observation \#2 $(890+1170) / 2=1030$ and according to observation \#27 $(1290+1440) / 2=1365$

${ }_{13}$ The confidence intervals are calculated from the results of the Monte Carlo experiment. The usual procedure is to calculate the asymptotic variances from the (inverse of the) Hessian matrix of the limiting
} 
Mean value of the initial year of the churchyard

Mean value of the terminal year of the churchyard

Lower limit for the initial year, $95 \%$ confidence

Upper limit for the initial year, $95 \%$ confidence

Lower limit for the terminal year, $95 \%$ confidence

Upper limit for the terminal year, $95 \%$ confidence
1041.5

1360.9

997.2

1097.7

1332.1

1412.4

Table 2. Estimated lower and upper end points of the period of use. Result of Monte Carlo experiment with maximum likelihood estimates of the initial and terminal years of use of Westerhus. The true initial year is assumed to be 1030, and the true terminal year 1365 .

The conclusion of the Monte Carlo experiment is that the estimator of the initial year is upward biased and that of the final year is downward biased. If the errors are normally distributed, the estimate of the initial year will, on average, be 11.5 years too high $(1041.5-1030)$, whereas the terminal year will have a downward bias of 4.1 years $(1360.9-1365)$. The length of the period of use of the churchyard will therefore be underestimated..$^{14}$ Furthermore, there will be a large confidence interval around the point estimates. For example, the initial year is surrounded by a $95 \%$ confidence interval of 100.5 years, while the terminal year has a confidence interval of 80.3 years.

Starting from the results of the Monte Carlo experiment, we can correct the estimates of the initial and terminal years according to Table 1. Further, we use the lengths of the calculated confidence intervals according to Table 2 and get the following results:

$\begin{array}{ll}\text { Estimated value of the initial year of the churchyard } & 1073.6 \\ \text { Estimated value of the terminal year of the churchyard } & 1355.7 \\ \text { Lower limit of the initial year, } 95 \% \text { confidence } & 1029.3 \\ \text { Upper limit of the initial year, } 95 \% \text { confidence } & 1129.8 \\ \text { Lower limit of the terminal year, } 95 \% \text { confidence } & 1326.9 \\ \text { Upper limit of the terminal year, } 95 \% \text { confidence } & 1407.2\end{array}$

Table 3. Estimated values of the initial and terminal years. The results are corrected for the bias of the maximum likelihood method.

The churchyard started to be used around 1074, and its use was approximately terminated in 1356. This means an increased length of use of 32 years as compared to Gejvall's assumption of 250 years, and a correspondingly greater increase as compared to the 200 years calculated by Kyhlberg \& Strucke. It should be stressed that the point estimates by Gejvall and by Kyhlberg \& Strucke, respectively, are

distribution of the maximum likelihood estimator. But since the sample is small (only 30 observations), we get higher precision by deriving the confidence interval from the Monte Carlo experiment.

${ }^{14}$ Note that the magnitude and direction of bias is related to the estimation method. The bias of the maximum likelihood method is, for example, different from that of "eye-estimation" referred to when arguing for the method of Kyhlberg \& Strucke. Moreover, the bias of a certain method may be related to parameter values. In Appendix 1 it is shown that the maximum likelihood method gives a positive bias for short true periods of use of a churchyard, whereas bias will be negative for long true periods of use. 
more or less inside the calculated confidence intervals. However, the terminal year of the main period suggested by Kyhlberg \& Strucke, 1292, is 35 years earlier than the lower value of the 95 per cent confidence interval of the terminal year, 1326.9. The terminal year suggested by Gejvall (1960), 1350, is close to our point estimate. The churchyard can very well have fallen out of use in connection with the Black Death.

The length of the confidence interval implies a significant uncertainty as to the exact dates since the estimate of the mean value of a population (e. g., the mean year of use of the churchyard, $M$ ) will be a function of all observations in the sample. This is in contrast to the case when we make point and interval estimates of the initial and terminal years of use of the churchyard. Here, only a few of the lowest measurement values will be involved when estimating $L$, and a few of the highest measurement values will be of direct significance when estimating $U .{ }^{15}$

The maximum likelihood estimates are derived on the assumption that measurement errors are normally distributed. However, the assumption is not fulfilled for measurements errors after calibration. For an analysis of the problem, see Appendix 1 below.

\section{${ }^{14} \mathrm{C}$ AND ARCHAEOLOGICAL DATING}

As stressed by Kyhlberg \& Strucke (2000), it is important to confront the individual ${ }^{14} \mathrm{C}$-measurement with archaeological evidence (e. g., the localization of the grave in the churchyard, the posture of the skeletons et cetera).

Only 30 of a total of 364 skeletons (the 7 fetuses are not included in this figure) in the Westerhus churchyard are radio-metrically dated. The small sample does not necessarily mean a low precision of the estimated time during which the churchyard was in use. For example, Iregren and Redin chose the skeletons for the ten latest obtained dates so that they would hopefully represent the end of the period of use of the churchyard. ${ }^{16}$ Consequently, archaeological information is important so as to minimize the sampling error of the estimates.

The ${ }^{14} \mathrm{C}$-dates do not necessarily represent the years of burial, see Kyhlberg \& Strucke (2000). Due to accumulation, the dates can represent a longer or shorter period before the burial. The ${ }^{14} \mathrm{C}$-value of a skeleton may have been accumulated during a varying number of years before the year of death. However, the $\mathrm{d}^{13} \mathrm{C}$ values according to Possner \& Söderman (2001), -19.4 - -21.6, indicate a low input of maritime food, which would imply that the accumulation problem is of

\footnotetext{
${ }^{15}$ The number of observations directly involved when estimating the lower end point, for example, is automatically determined when maximizing the likelihood function.

${ }^{16}$ The choice can be made in various ways. One is related to the distance to the chapel. The first graves were presumably dug close to the chapel. The churchyard was then extended from the chapel. However, positions close to the chapel were considered more honorable than those at a greater distance. There was therefore a social dimension. Moreover, some of the graves may have been dug before the chapel was erected. In addition the dept of the grave could give an indication of whether it was dug in an earlier or a later phase of the development of the churchyard, see Gejvall (1960:71-72).
} 
smaller significance than for a coastal population. Nevertheless, it is safe to add a number of years to the ${ }^{14} \mathrm{C}$-dates, especially for individuals of old age. This does not mean that the estimated duration of use of the churchyard is increased, but only that we should add a correction term to the estimated lower and upper end points of the period of use.

\section{CALCULATION OF MORTALITIES}

The number of living people in a settlement can be calculated if we know how many years the churchyard has been used and the magnitude of mortality. A given number of graves represents a small number of simultaneously living people if the period of use is long and/or mortality is high.

Osteologically estimated lifetimes of the buried individuals form the basis for mortality calculations. Table 4 summarizes the dead distributed according to seven osteological age groups according to Gejvall $(1960, \mathrm{~T} 1) .{ }^{17}$ However the slightly revised osteological age limits of Sjøvold (1978) have been used.

$\begin{array}{lccc}\text { Age group } & \text { Men } & \text { Women } & \text { Not sex evaluated } \\ \text { Infant, 0 } & 0 & 0 & 113 \\ \text { Infans I, 1-7 } & 0 & 0 & 70 \\ \text { Infans II, 8-14 } & 0 & 0 & 27 \\ \text { Juvenis, 15-20 } & 12 & 3 & 0 \\ \text { Adultus, 21-40 } & 28 & 41 & 0 \\ \text { Maturus, 41-60 } & 29 & 36 & 0 \\ \text { Senilis, 61- } & 2 & 3 & 0 \\ \text { Total } & 71 & 83 & 210\end{array}$

Table 4. The dead in Westerhus distributed in non-overlapping osteological age groups.

Now, assume that mortality is constant for a certain sex within a certain osteological age group. We can then use the maximum likelihood method to estimate the sex and age differentiated mortalities which maximize the likelihood of finding the observed number of dead according to the distribution in Table $4 .{ }^{18}$ The result is given in Table 5 .

Mortalities in Westerhus were strikingly high. For example three out of ten new-born babies were expected to die during their first year of life. Mortalities then decreased with increasing age up to the age of 15 for men and 20 for women. The higher mortalities for women than men in the age group 21-40 might possibly be connected with higher risks in connection with child-birth.

Knowing the mortalities for men and women of different age groups, it is then

\footnotetext{
${ }^{17}$ For a discussion of a more detailed age estimate of the dead children based on the development of teeth, see Alexandersen \& Iregren (2000).

${ }^{18}$ See Siven (1991a) for a maximum likelihood calculation based on the Westerhus material. For another example of the use of this method, see Konigsberg \& Frankenberg (1992). For a recent survey of the area, see Meindl \& Russell (1998).
} 


\begin{tabular}{crr} 
Age group & \multicolumn{3}{c}{ Mortality } \\
& Men & Women \\
0 & 310.445 & 310.376 \\
$1-7$ & 45.445 & 45.635 \\
$8-14$ & 22.813 & 22.813 \\
$15-20$ & 30.390 & 6.120 \\
$21-40$ & 31.664 & 35.284 \\
$41-60$ & 128.026 & 120.344 \\
$61-$ & 316.007 & 328.945
\end{tabular}

Table 5. Age and sex differentiated mortalities for Westerhus. A stationary population is assumed. Source: Own calculations.

possible to calculate the age distribution of the living. Table 6 presents the results for Westerhus. As a comparison the corresponding figures are given for Sweden during the second half of the $18^{\text {th }}$ century and for Sweden 2003.

$\begin{array}{lccc}\text { Age group } & \text { Westerhus } & \text { Sweden } 1750-90 & \text { Sweden } 2003 \\ 0-4 & 19.36 & 12.54 & 5.27 \\ 5-9 & 14.65 & 10.41 & 5.59 \\ 10-14 & 12.67 & 9.82 & 6.96 \\ 15-19 & 11.42 & 9.06 & 6.16 \\ 20-29 & 18.97 & 16.41 & 11.99 \\ 30-39 & 13.49 & 13.74 & 14.21 \\ 40-49 & 7.16 & 10.91 & 13.16 \\ 50-59 & 1.94 & 8.30 & 13.86 \\ 60-69 & 0.33 & 5.09 & 10.05 \\ 70- & 0.01 & 3.17 & 12.76\end{array}$

Table 6. Distribution in percent of all living persons in five- and ten-year classes for Westerhus, Sweden 1750-90 and Sweden 2003. Each column adds up to 100. A stationary population is assumed for Westerhus. Sources: Statistics Sweden (1969:68), Statistics Sweden home page www.scb.se and own calculations.

The figures for Westerhus are calculated under the assumption of a stationary population with no migration. We see that the proportion of young people in Westerhus is much higher than for Sweden 1750-90. The difference is even greater if we compare with Sweden 2003. A main reason for this is that mortalities were much higher during the Middle Ages. But especially regarding Sweden 2003, migration and being non-stationary affect the figures. The growth of population may also affect the age distribution. This means that we have to make a number of assumptions in order to make population calculations for Westerhus. These assumptions will be discussed below.

\section{A CLOSED POPULATION}

For the dead to represent those who once lived in the settlement of Westerhus, there should be no migration. Otherwise some of the buried in Westerhus could come from other places and thus represent other living populations. For a nonclosed population some of those once living in Westerhus would also be buried at other places. However, the strict assumption of a closed population is not 
necessary for the calculations to hold. What we do need to assume is that there is no age- and sex-dependent net migration. For example, we may very well assume a high migration propensity for women in connection with marriages. This mobility was probably concentrated to the age interval 15-25. However, the young women leaving Westerhus would on the whole balance those coming to Westerhus.

The problem is more severe for men. The number of sex-evaluated men in Westerhus is, namely, slightly lower than the corresponding number of women (71 and 83, respectively). The missing men may have died during hunting expeditions or in connection with war. The number of men belonging to Westerhus but buried at other places might be even larger. Women were buried to the north of the chapel, but a part of this area does not contain any graves. If this absence is due to later disturbances, the imbalance between the sexes is even greater.

Even if the problem of making population calculations in the presence of migration probably is less severe for Westerhus than for urban medieval churchyards, we still draw the conclusion that the calculations below may be affected.

\section{POPULATION GROWTH}

Growth of population may affect average mortality and thus the estimated population since the age distribution will change. For example, the higher the rate of growth, the greater will be the proportion of children. This can be seen in many underdeveloped countries of today. Since mortalities vary according to age, a changed age distribution will consequently affect the average mortality of the population.

In the calculations presented below the effect of population growth on the results of the calculations will be accounted for. But how can we get information about the development of population at Westerhus? One possible way is Redin's (2000) study of the positioning of the arms of the dead. It seems that usage has changed over time, and if there is a great number of "later" positionings in comparison to earlier ones we might draw some conclusions regarding growth of the population. However, dating by this method is uncertain. One of the reasons is that the different usages have not dominated during different times; there are overlappings.

Another possibility of estimating the development of the population at Westerhus would be to use the $30{ }^{14} \mathrm{C}$-dates. One could, for example, split the period of use into two equally long periods and then use the number of ${ }^{14} \mathrm{C}$-values belonging to the later period in comparison to the earlier one to estimate the rate of growth. This is in principle a promising avenue, but the procedure presupposes that the ${ }^{14} \mathrm{C}$-dates were obtained by random sampling. Since this is not the case we cannot know if, for example, a great number of dates from the latter part of the period of use is due to population growth or due to the fact that a great number of graves from the latter part of the period were consciously chosen in order to get a good estimate of the end point of the period of use.

Lacking a good estimate of the rate of growth of the population of Westerhus, 
we will instead see how our conclusions as to the population are affected by the assumed rate of growth. The assumption about the rate of growth will not be made randomly but instead conform to what can reasonably be believed, see the discussion below.

\section{CONSTANT AGE AND SEX DISTRIBUTION}

The calculations below will be based on the assumption of a constant age and sex distribution. This means either a stationary population or a balanced growth population. We can be pretty sure that the assumption is not fulfilled in reality. A disturbance in the form of a baby boom such as experienced during the 1940s will, for example, create echo effects 20-30 years later so that the age distribution will change in a cyclical manner. However, when left undisturbed the population will in the long run converge to a constant age and sex distribution. Moreover, below we will discuss the effects of transient changes of the age distribution. At this point we leave the discussion of the assumptions on which the calculations are based and turn to the results of the calculations. We will first discuss a constant and then a growing population. In both cases we will discuss the possibility that the agglomerations of children's graves represent "mass graves".

\section{DURATION OF USE AND SIZE OF POPULATION: NO POPULATION GROWTH}

According to Table 3, the churchyard was in use for about 280 years. It is true that there is a significant uncertainty margin around this figure, but it constitutes a reasonable starting point as a basic result. It is then possible to calculate the living population, if we know its average mortality.

For a stationary population, we can calculate the number of simultaneously living people, $P_{t}$, if we know the mortality, $d$, the length of time during which the churchyard was in use, $T$, and the total number of buried people, $B$ :

$P_{t}=\frac{1}{T} \cdot B \cdot \frac{1000}{d}$

We already know the number of buried people. The same holds for the estimated length of time the churchyard was in use. The average mortality can be calculated from the age and sex differentiated mortalities according to Table 5. This is done via an intermediate calculation of the age distribution of the once living population.

For a stationary population, substitution in (5) gives us the number of simultaneously living people, slightly more than 23 individuals. This can be compared with the number obtained if we assume that the churchyard had instead been in use for 250 years. In this case, we obtain a 13\% larger population, namely approximately 26 individuals. Since we can also calculate the age distribution of the living population, it is possible to estimate the share of children below the age of 15 . Assuming a stationary population, we get 10 to 11 children in the former case and 12 children in the latter. Consequently, this is the maximum number of children who could die and be buried in the same year. If we finally start from the 
lower end point of the $95 \%$ confidence interval, the length of the period of use will be 205.3 years. The number of living people will then be approximately 32 , and the number of children slightly less than 15 .

\section{DURATION OF USE AND SIZE OF POPULATION: POPULATION GROWTH}

If the population is instead growing, there will be two differences. First, the population will naturally be larger at the end than at the beginning of the period. For the end of the period, this makes room for a greater number of children than for a stationary population. Second, the share of children will be larger in a growing than in a stationary population. The higher the growth of the population, the larger the share of the young, see Siven (1982). The population at the point in time $t, P_{t}$, can be calculated according to the following formula:

$P_{t}=\frac{(k-1) \cdot B}{k^{T}-1} \cdot k^{t-1074} \cdot \frac{1000}{d}$.

Here, $k=(1+\lambda / 1000)$ and $\lambda$ is the yearly rate of growth in per thousand. The initial year of the churchyard is assumed to be 1074 .

With a yearly rate of growth of 0.3 percent $^{19}$ and a period of 282 years, the population will increase from about 15 individuals to about 35 from the beginning to the end of the period. At this rate of growth, the share of children will constitute slightly more than $48 \%$ of the simultaneously living population (as opposed to slightly less than $48 \%$ with a stationary population). This means that the maximum number of children that could be buried in the same year at the end of the period is around 17. Since the six grave agglomerations consist of $6,10,11,14,22$ and 23 individuals, the smaller graves are consistent with the calculated number of children in the simultaneously living population. In contrast, the two largest graves do not seem to be consistent with the calculated population. ${ }^{20}$ Further, it should be noted that the duration of use of the churchyard in the above examples possibly implies an underestimate, due to the sampling error. Consequently, the number of living people and children could be even smaller than in the above examples.

\section{THE CASE OF NON-CONSTANT AGE AND SEX DISTRIBUTION}

The conclusions above are based on the assumption that the population is stationary or has grown at a constant rate, with constant age and sex distribution; that is, steady-state growth. It is conceivable that the Westerhus population has been subject to a series of shocks where mainly the children have been affected. The

\footnotetext{
${ }^{19}$ As a comparison, 0.7 percent growth implies a doubling of the population in 100 years. Benedictow (1996:182) estimates a yearly rate of growth of 0.2 percent for the Scandinavian countries during the period $700-1300$.

${ }^{20}$ If we still assume the rate of growth of the population to be 0.3 percent per year, but change the period of use from 282 years to 205 years (the lower end point of the $95 \%$ confidence interval), the number of people at the end of the period of use will be between 41 and 42 and the number of children slightly less than 20 . This will still be less than the number of children in the two largest grave agglomerations.
} 
age (and possibly the sex) distribution has not been constant in this case. A year when a great number of children have died will affect the age distribution for many years to come. Furthermore, the possible mass burials must have taken place with long intervals for the number of simultaneously living children to be large enough to explain the great number of buried children. Another consequence is that the graves no longer represent a constant population or a population in steady-state growth. It must instead have fallen drastically in one year. At the same time, the rate of growth must have been greater than the long-time average between the recurrent population shocks. This is one possibility of making the mass burials of children conform to the calculated average number of people.

However, this will not do as an explanation since a majority of the buried individuals died in the first year of their life. For example, grave agglomeration E89 contained 10 children less than one year old and 2 fetuses; grave agglomeration To contained the skeletons of 12 small children and 1 fetus; grave agglomeration $D E$ contained 17 children who had died in their first year of life as well as 1 fetus; see Gejvall (1960:T1). If, just for the sake of argument, we assume the population to be 35 individuals and $25 \%$ of these to be women of fertile age, there would be 9 women to give birth to a child during one year. If we disregard twins and, in addition, assume that for a woman there will be more than a year between each birth (including premature births), the maximum number of children born in a certain year would be $9 .^{21}$ This shall be compared with 12,13 and 18 children, respectively. The conclusion is that if the children were buried during the same season, some of them must come from outside the Westerhus population. The alternative is that they were not buried during the same season. The former hypothesis implies that some very young children were buried in Westerhus, despite belonging to another population. ${ }^{22}$ The reason might be that there was some sort of hospital at Westerhus, perhaps connected with the pilgrim route to Trondheim. This does not seem very likely, however. We therefore arrive at the latter hypothesis, that the closely buried children were not buried during the same season. The fact that women older than 14 years were buried to the north and men to the south of the church suggests that small children may have been buried rather close to each other in certain areas of the churchyard. In that case, the six agglomerations of small children should not be interpreted as "mass graves". ${ }^{23}$

\section{SUMMARY AND CONCLUSIONS}

The most important contribution of this paper is a method for estimating the period of use of a burial-ground field or a churchyard when the starting point is

\footnotetext{
${ }^{21}$ For a discussion of the number of births per woman and the time span between the successive births of a given woman at Westerhus, see Siven (1991b). During the most productive years (in the age interval 2535), the women of Westerhus bore a child every 3 years, see Siven (1991b:114).

${ }^{22}$ In this case, those buried in Westerhus would not represent a closed population.

${ }^{23}$ Unfortunately, the excavation of Westerhus was not properly documented. It is therefore impossible to obtain decisive archaeological information on the issue.
} 
a series of ${ }^{14} \mathrm{C}$-dates. This is a special case of a more general question: how can we combine individual ${ }^{14} \mathrm{C}$-dates to answer various archaeological questions? The estimator is derived with the help of the maximum likelihood method. The properties of the estimator have been evaluated by a series of Monte Carlo experiments. A diagnostic test has been made on the basis of Göran Skog's OxCal simulation.

The point estimates of the initial and the terminal year for the period of use of the churchyard are surrounded by broad confidence intervals (95-percent level). However, we can still say that the estimated initial year, 1074, and the terminal year, 1356, on the whole conform to Gejvall's (1960) opinion of the period of use. The churchyard came into use in connection with or not long after the introduction of Christianity in the Swedish province of Jämtland. The adoption of Christianity in Jämtland took place sometime in the middle of the eleventh century as indicated by a runic stone at Frösön, see Jansson (1976:119). For further discussion, see Brink (1996) and Welinder (2004). Considering the broad confidence interval, the estimated terminal year conforms well to the occurrence of the Black Death.

Osteological evaluations of the age at death and the sex of the buried individuals can be used to estimate the age and sex distribution of the once living population and its age and sex differentiated mortalities, see Siven (1991a, 1991b). If we combine these results with the estimated period of use of the churchyard, we can estimate the total number of (once) living people at the site. This information can be used to answer different archaeological and historical questions.

If we accept the period of use suggested by Gejvall (1960) or, as here, an even longer period of use, it is difficult to explain the "mass burials" of children. Gejvall (1960:38) thought that they could possibly be dated to a period after the main use of the churchyard. However, as argued by Iregren \& Redin (1999), this is difficult to reconcile with the results of the (few) ${ }^{14} \mathrm{C}$-dates as regards the "mass graves". If we abandon the assumption that the population is in steady-state growth, the results might be different. However, since a majority of the buried children were in their first year of life, it seems that the number of women of fertile age in Westerhus simply does not suffice. Either the children come from other sites or they were not buried in the same season. The second alternative seems more likely, but the exact interpretation of the grave agglomerations is still uncertain.

\section{English revised by Laura Wang.}

\section{ACKNOWLEDGEMENTS}

I am grateful to Elisabeth Iregren and Lars Redin who suggested the topic of this paper and helped me in the initial phase of the work. I am also grateful for comments from Verner Alexandersen, Ebba During, Elisabeth Iregren, Christina Lönnblad, Mats Persson, Göran Skog, Peter Skogman Thoursie and Stig Welinder. The map has been drawn by Kristina Berglund. 


\section{APPENDIX 1. DIAGNOSTIC TEST OF THE EFFECT OF THE FUNCTIONAL FORM OF THE MEASUREMENT ERRORS}

The maximum likelihood estimate presented in this paper is based on the assumption that the measurement errors are normally distributed. However, after calibration, the measurement errors have more complicated functional forms, which also differ between observations. To get an indication of how the assumption of normally distributed errors may affect the result, we have used an OxCal simulation by Göran Skog at the ${ }^{14} \mathrm{C}$-laboratory of Lund University. The starting point is 30 random observations from a normal distribution with the mean 1190 and the standard deviation $80{ }^{14} \mathrm{C}$-years. Thereafter, the 30 calibrated density functions were derived. How good an estimate will the maximum likelihood method produce? The ideal result would be to get the estimated initial and terminal years of the period of use at 1190 , but the measurement errors would make us miss the target somewhat. The result obtained was that the churchyard started to be used at the beginning of 1151 and remained in use for about a month. This is a remarkable result. Due to the random errors and the fact that the estimated duration of use of the churchyard is restricted to be positive, we would expect a longer estimated duration of use despite the true period of use being of zero duration. Further, the true point in time when the churchyard was in use according to Skog's experiment is almost 40 years later than the estimated one. This difference may be due to four interacting causes: (1) we have not used the correct functional form of the probability density functions of the errors but approximated those with the normal distribution; (2) the maximum likelihood method in this case gives a negatively biased estimator; (3) Skog's figures are rounded to the closest multiple of 10; and (4) random errors.

In order to make the diagnostic test, we first need to know the bias of the maximum likelihood estimator for this case. Therefore, we have made a Monte Carlo experiment with 60,000 iterations assuming all graves to be from 1190 and the standard deviation of the measurement errors to be 80 for all observations. ${ }^{24}$ The results are summarized in Table Al.

From Table A1, we see that the maximum likelihood estimator for the length of the period of use is biased by approximately 48 years $(1214.0-1166.1)$. The estimate of the initial year will generally be placed 23.9 years too early and the estimated terminal year 24 years too late. If we compare the results of the Monte Carlo experiment with the estimate based on Skog's calibrated data where the initial and terminal years are placed in 1151 , we see that the initial year is situated in the interior of the confidence interval according to Table 4, but that the terminal

\footnotetext{
${ }^{24}$ This can be compared to the average year of the calibrated estimates, 1197.5, and the average standard deviation of the 30 distributions, 58.9. Skog consequently assumed a larger standard deviation in his $\mathrm{OxCal}$ simulation than the average standard deviation of the 30 calibrated observations from Westerhus. This means that the measurement errors and, consequently, the possible bias of using the normal distribution connected with his simulation are larger than that connected with our estimate of the duration of use of the churchyard.
} 
Mean value of the initial year of the churchyard

Mean value of the terminal year of the churchyard

Lower limit of the initial year, $95 \%$ confidence

Upper limit of the initial year, $95 \%$ confidence

Lower limit of the terminal year, $95 \%$ confidence

Upper limit of the terminal year, $95 \%$ confidence
1166.1

1214.0

1083.7

1215.2

1164.8

1297.3

Table A I. Result of Monte Carlo experiment with a maximum likelihood estimate of the initial and terminal years of use of Westerhus. The true initial and terminal years of use are both assumed to be 1190. The standard deviation equals 80 for all observations.

year is about 14 years earlier than the lower limit of the confidence interval of the terminal year. This may be a random effect, but the availability of calibrated density functions (instead of approximating them with the normal distribution) would be likely to give a certain difference. The conclusion is that using the calibrated probability density functions instead of the normal function may make some difference, since random errors are unlikely to completely explain the too early estimated period of use. However, some part of the difference may be due to rounding errors when presenting the calibrated ${ }^{14} \mathrm{C}$-values.

The experiment to check the bias of the maximum likelihood estimator used on Skog's data gave the result of a bias away from the origin. We got too long a period of use for the churchyard. This is in contrast with our first Monte Carlo experiment, where the estimator tended to underestimate the duration of use. To check how the bias is related to the true length of the period of use, I have made a series of 11 Monte Carlo experiments. Here, the duration of use varies from 0 to 335 years. The standard deviation is assumed to equal 58.917 (the average of the standard deviations calculated from Appendix 1) for all observations. The number of iterations is 60,000 . We get the following result:

$\begin{array}{lccc}\text { True starting year } & \text { Average estimated starting year } & \text { True final year } & \text { Average estimated final year } \\ 1197.5 & 1187.0 & 1197.5 & 1218.7 \\ 1180.8 & 1183.7 & 1214.3 & 1221.9 \\ 1164.0 & 1177.3 & 1231.0 & 1228.3 \\ 1147.3 & 1165.4 & 1247.8 & 1240.3 \\ 1130.5 & 1149.7 & 1264.5 & 1256.1 \\ 1113.8 & 1131.3 & 1281.3 & 1274.6 \\ 1097.0 & 1113.5 & 1298.0 & 1292.8 \\ 1080.3 & 1196.8 & 1314.8 & 1310.3 \\ 1063.5 & 1080.7 & 1331.5 & 1327.4 \\ 1046.8 & 1065.1 & 1348.3 & 1344.4 \\ 1030.0 & 1049.7 & 1365.0 & 1361.5\end{array}$

Table A2. Result of Monte Carlo experiments with a maximum likelihood estimation of the initial and terminal years of use of Westerhus. The standard deviation equals 58.917 for all observations.

We see that the bias is a function of the true starting and true final years of the period of use, respectively. The longer the period of use, the more the length of the period tends to be underestimated. 


\section{APPENDIX 2. LIST OF THE 30 CALIBRATED ${ }^{14} \mathrm{C}$-DATES}

\begin{tabular}{|c|c|c|c|c|}
\hline Observation & Grave \# & Notation & Calibr. year min & Calibr. year max \\
\hline 1 & 171 & St 2144 & 890 & 1190 \\
\hline 2 & 4 & Ua 15062 & 890 & 1170 \\
\hline 3 & 1 & Ua 15061 & 990 & 1220 \\
\hline 4 & To $\mathrm{i}$ (in the tower) & Ua 15068 & 980 & 1250 \\
\hline 5 & 206 & Ua 15066 & 1020 & 1270 \\
\hline 6 & E $89 \mathrm{~d}$ & Ua 15063 & 1020 & 1260 \\
\hline 7 & $89 a$ & St 1909 & 1020 & 1270 \\
\hline 8 & 91 & St 1919 & 1020 & 1270 \\
\hline 9 & E $89 \mathrm{~g}$ & Ua 15064 & 1030 & 1280 \\
\hline 10 & To a (in the tower) & Ua 15067 & 1030 & 1290 \\
\hline 11 & 32 & St 2149 & 1030 & 1290 \\
\hline 12 & $89 \mathrm{~b}$ & St 1923 & 1140 & 1390 \\
\hline 13 & 9 & St 2147 & 1060 & 1400 \\
\hline 14 & 96 & Ua 15065 & 1150 & 1390 \\
\hline 15 & 177 & St 2148 & 1150 & 1400 \\
\hline 16 & 117 & St 2146 & 1160 & 1400 \\
\hline 17 & 54 & St 2141 & 1210 & 1410 \\
\hline 18 & 181 & St 2145 & 1240 & 1410 \\
\hline 19 & 225 & St 2142 & 1260 & 1420 \\
\hline 20 & 104 & St 2143 & 1220 & 1440 \\
\hline 21 & 5 & Ua-1 18298 & 1030 & 1300 \\
\hline 22 & 51 & Ua-18299 & 1160 & 1410 \\
\hline 23 & 69 & Ua- 18301 & 1280 & 1420 \\
\hline 24 & 52 & Ua- 18300 & 980 & 1250 \\
\hline 25 & 130 & Ua- 18303 & 1030 & 1270 \\
\hline 26 & 123 & Ua- 18302 & 1110 & 1290 \\
\hline 27 & 159 & Ua- 18305 & 1290 & 1440 \\
\hline 28 & 134 & Ua- 18304 & 1110 & 1290 \\
\hline 29 & 223 & Ua- 18306 & 1020 & 1250 \\
\hline 30 & 227 & Ua-18307 & 1030 & 1280 \\
\hline
\end{tabular}

Note: Calibrated year min means that $2.3 \%$ of the probability mass is situated to the left of this value. In a corresponding way, calibrated year max means that $2.3 \%$ of the probability mass is situated to the right of this value. If the probability density function of the measurement values is normally distributed, this means that these values are situated at the mean value $\pm 2 \sigma$. The first 20 observations are those presented by Kyhlberg \& Strucke (2000), the 10 last are produced by the Ångström Laboratory in Uppsala, see Possner \& Söderman (2001). 


\section{REFERENCES}

Alexandersen, V. \& Iregren, E. 2000. Westerhus - Børnenes tænder (Westerhus - the teeth of the children). In: Dalerup Koch, H. (Ed). Middelalderens kirkegårde. Arkeologi og antropologi-insigt og udsyn. Forlaget Hikuin, Højbjerg.

Antonsson, H. 2004. Landskap och ödesbölen. Jämtland före, under och efter den medeltida agrarkrisen (Landscape and deserted settlements. Jämtland before, during and after the Medieval agrarian crisis). Kulturgeografiska institutionen, Stockholms universitet, Stockholm.

Benedictow, O. J. 1996. The Demography of the Viking Age and the High Middle Ages in the Nordic Countries Scandinavian Journal of History 21 Pp. 151-182.

Berthelson, B. 1952. Kyrkoruinen i Västerhus (The church ruin in Västerhus). In: Arkeologiska forskningar och fynd. Studier utgivna med anledning av H. M. Konung Gustav VI Adolfs sjuttioårsdag 11. 11. 1952. Stockholm.

Boldsen, J. 2000. Demografisk struktur i landsbyen Tirup (Demographic structure in the village of Tirup. In: Dalerup Koch, H. (Ed). Middelalderens kirkegårde. Arkeologi og antropologi - insigt og udsyn. Forlaget Hikuin, Højbjerg.

Brink, S. (Ed).1996. Jämtlands kristnande (The christianization of the province of Jämtland). Lunne böcker, Uppsala.

Cramer, J. S. 1986. Econometric Applications of Maximum Likelihood Methods. Cambridge University Press, Cambridge.

Gejvall, N. G. 1960, Westerhus, Medieval Population and Church in the Light of Skeletal Remains. Kungl. Vitterhets Historie och Antikvitets Akademien, Stockholm.

- 1968. Early Medieval church at Westerhus in the light of the C14 collagen datings. In: Res mediaevales. Ragnar Blomqvist kal. Mai. MCMLXVIII oblata. Lund.

Iregren, E. \& Redin, L. 2000. Assemblages of children's bones in a Medieval churchyard in Sweden Results of epidemics, warfare, infanticide or simply, disturbed graves?). In: Varela, T. A. (Ed). Investigaciones Biodiversidad Humana 2000. Santiago di Compostela.

Iregren, E. \& Jungner, H. \& Räisänen, J. \& Alexandersen, V. 2000. Dieten hos barn och vuxna i Westerhus (The diet of children and grown-ups in Westerhus). In: Dalerup Koch, H. (Ed). Middelalderens kirkegårde. Arkeologi og antropologi - insigt og udsyn. Forlaget Hikuin, Højbjerg.

Jansson, S. B. F. 1977, Runinskrifter i Sverige (Runic inscriptions in Sweden). AWE/Gebers, Uppsala.

Konigsberg, L. W. \& Frankenberg, S. R. 1992. Estimation of Anthropolgical Demography. American Journal of Physical Anthropology 89. Pp. 235-256.

Kyhlberg, O. \& Strucke, U. 2000. Teoriprövning med ${ }^{14} \mathrm{C}$ (Theory test using ${ }^{14} \mathrm{C}$ ). In: Dalerup Koch, H. (Ed). Middelalderens kirkegårde. Arkeologi og antropologi - insigt og udsyn. Forlaget Hikuin, Højbjerg.

Meindl, R. S. \& Russell, K. F. 1998. Recent Advances in Method and Theory of Paleodemography. Annual Review of Anthropology, 27. Pp. 375-399.

Myrdal, J. 2003. Digerdöden, pestvågor och ödeläggelse (The Black Death, plauge waves and desolation). Sällskapet Runica et Mediævalia, Stockholm.

Possner, G. \& Söderman, M. 2001. Resultat av ${ }^{14} \mathrm{C}$ datering av ben från Jämtland (Result of ${ }^{14} \mathrm{C}$-dating of bones from Jämtland), PM from the Ångström Laboratory, Uppsala, 2001-09-19.

Redin, L. 2000. Arkeologiska perspektiv på Västerhus ödekyrkogård på Frösön i Jämtland (Archeological perspectives of Västerhus' deserted churchyard in Frösön in Jämtland). In: Dalerup Koch, H. (Ed). Middelalderens kirkegårde. Arkeologi og antropologi - insigt og udsyn. Forlaget Hikuin, Højbjerg.

Severini, T. A. 2000. Likelihood Methods in Statistics. Oxford University Press, Oxford.

Siven, C-H. 1982. Metoder för beräkning av förhistoriska populationer (Methods for calculating prehistoric populations). Arkeologiska rapporter och meddelanden från Institutionen för arkeologi vid Stockholms universitet, 10.

- 1991a. On estimating mortalities from osteological age data. International Journal of Anthropology, 6. Pp. 97-110.

-1991b. On reconstructing the (once) living population from osteological age data. International Journal of Anthropology, 6. Pp. 111-118. 
Sjøvold, T. 1978. Inference Concerning the Age Distribution of Skeletal Populations and some Consequences for Paleodemography. Anthropologiai Közlemenyek, 22. Pp. 99-114.

Statistics Sweden. 1969. Historisk statistik för Sverige. Del 1 Befolkning (Historical statistics for Sweden. Part I Population). Stockholm.

Welinder, S. 2004. Christianity, Politics and Ethnicity in Early Medieval Jämtland, Mid Sweden. In: Martin Carver (Ed). The Cross Goes North. Processes of Conversion in Northern Europe, AD 300-1300. York Medieval Press. 